\title{
Issues and Implications in an Information Technology Outsourcing Relationship
}

\author{
Muhammad Adeel Javaid \\ Member Vendor Advisory Council, CompTIA \\ *Corresponding Author: ajaviad@gmail.com
}

Copyright (C) 2014 Horizon Research Publishing. All rights reserved.

\begin{abstract}
IT outsourcing is an arrangement in which a company subcontracts its information technology related activities to be executed by a different company. In the past several decades, as the role of information technology grew in the performance of a company, the fixed cost of maintaining up and running IT facilities and staffs was increasing as well. Therefore outsourcing solution was derived from companies' need to achieve superior performance of IT functions with minimum amount of cost. Major classifications of IT functions that companies outsource are infrastructure and applications. Infrastructure outsourcing refers to a company resolving its entire IT activities handled by a contracted vendor company on the company's behalf. Application outsourcing stands for a company subcontracting only its core IT applications such as ERP systems, document management systems or Business intelligence applications with service provider. Though the IT Outsourcing process might be a useful activity for the growth and resources of a service provider's organization but at the same time it has some issues with multiple implications that need to be analyzed in detail. In this paper we take a look at IT Outsourcing process and analytically evaluate its effects on future growth of an organization.
\end{abstract}

Keywords IT Outsourcing, IT Contracts

\section{Introduction}

Outsourcing denotes a business practice in which organizations contract other specialists or companies to get part of their works accomplished. Outsourcing has gained a lot of popularity due to various reasons, however; despite the outsourcing of most elements of the business process organizations have mainly retained the core aspects of the organization whilst outsourcing on no-core processes or procedures. The companies receiving the outsourced aspects usually act as specialists in the areas of operation that they provide these services in. The process is at times popularly referred to as "facilities management" or "contracting."
Therefore, organizations that outsource cease to perform the tasks for which they seek services and instead purchase them as any other services purchased by the organization. Outsourcing begun at the turn of the $21^{\text {st }}$ century, but is now a common and popular option in the modern economy. It is common for outsourcing to be confused with off-shoring, which is quite different. As a matter of differentiation, off-shoring entails the relocation or movement of an organizations' business functions to another nation-in this case the nation may be offshore or not. Contrastingly, outsourcing is either domestic or foreign. Firms offering outsourcing services needed by organizations are referred to as third-party party service providers or simply service providers. The organizations seeking these services may therefore tie up with the third-party providers for whole projects or just individual processes.

Outsourcing may take on three broad forms in business, and these are KPO ("Knowledge Process Outsourcing"), BPO ("Business Process Outsourcing") and ITO ("Information Technology Outsourcing"). Business process outsourcing entails offering a third-party the role of running particular business processes for example, payroll related tasks or purchases. The processes may either be front office or back office processes. The back office roles may include activities such as purchase and billing. On the other hand, front office roles may include processes such as answering customer calls, marketing or offering technical support on products-these are mainly consumer oriented tasks. Activities that can be placed BPO include call centre services, marketing, proofreading, animation/multimedia, web design, logo designs, typesetting, medical billing, business consultancy and book keeping-just to mention, but a few. In essence, BPO entails undertaking standardized processes on behalf of the clients that seek outsourcing services. On the other, hand KPO involves outsourcing tasks that require high involvement levels from the service provider. Under KPO the work involves greater technical and analytical skills and the worker has to be involved in the making of high decisions-higher than would be in a BPO case. Typical examples involve development of software, simulation, pharmaceutical development and research, data analysis, legal services, database development, animation and a 
multitude of other research related works. In actual sense KPO may have been around for longer and more developed than KPO. ITO commonly entails the outsourcing of tasks that are related to IT such as software development, web design, database development and a lot more-notably ITO could be shadowed by BPO and KPO and thus be a sub-set of the two depending on the tasks involved. According to Nancy, when outsourcing gained popularity in the early 90's, it mainly entailed the development of software at a cheaper rate in locations that offered low-cost services. The trend of outsourcing coupled with off-shoring greatly increased in the early 2000's to solve greater needs in the Information Technology (IT) industry. IT outsourcing has been lauded for the reduction of costs of operation, increased flexibility in IT management and an increase in service levels.

Information technology outsourcing denotes the process of transferring decisions rights or property rights in different degrees over IT infrastructure development and use by the user-organization to an external organization. IT outsourcing is not a very new feature in the business world and its onset can be traced back to the 70s and 60s when the purchase of computer time sharing started. These initial forms of outsourcing were mainly for companies that did not have IT in infrastructure, but it is now common for even big firms with comprehensive structural set ups to outsource their IT functions. The true representative of current outsourcing practices and icon of success in I. T outsourcing began in the 1980s. This is when Kodak outsourced its IT functions in 1989 to International Business Machines (IBM). This was a landmark deal that laid ground for the current world of outsourcing. After this landmark in outsourcing business the IT outsourcing industry has grown by an estimated $\$ 40$ billion US dollars. Since this initiation more and more organizations such as British aerospace and Xerox have taken the same route and experienced great success. IT outsourcing arrangements usually take two forms, and these are vendor contracting or traditional outsourcing and quasi-outsourcing, which entails the setting up of a subsidiary of the organization specializing only on IT functions, but as a separate and independent entity. Quasi-outsourcing frees former departments dealing with IT within organizations to act as free entities free from bureaucratic restrictions related to support functions on the organization's value chain. The different options of IT outsourcing sought depend on the abilities of an organization, needs and managerial decisions based on the situation evident within each organization, but definitely the results differ and the success of each method differ depending on the ground conditions.

\section{Drivers of Outsourcing Popularity}

The developments in communications and computing have greatly transformed the telecommunication industry and changed the manner in which people work. This has altered the way people communicate; create records, store records and transfer information. The developments in computing and telecommunication have been the major influence behind the development of outsourcing within most workplaces. The use of the World Wide Web permitted people across the globe to use the same applications and thus allowing the provision of services around the globe on common platforms. As such, it may be stated that technology, especially in IT has been the major driver behind outsourcing. The private sectors' drive to outsource is driven by various factors such as seeking competitiveness, business process re-engineering (BPR) and the desire to develop greater emphasis on core businesses. In the public domain the drive to outsource is influenced by reduction of administration costs in places such as the health sector, marketing test programs and competitive tendering within local governments. Cost effectiveness, enhanced flexibility and the need to focus on core business operations have been cited as the two most common reasons why organizations seek outsourcing. The core drivers in this case are either politically driven as in government sectors and efficiency driven as proposed by managerial decisions such as those based on BPR Despite the success associated with outsourcing, there are also numerous challenges that come with it. For example, USX and Sears failed to spin off a successful quasi-outsourcing section of their businesses mainly because of lack of external customers to complement their core function of serving their parent companies. Therefore, not all outsourcing aspects get success.

\section{Challenges and Success Factors Associated with IT Outsourcing (ITO)}

A large number of business organizations are everyday increasing their outsourced IT functions. This is due to the resultant benefits such cost effectiveness, high client satisfaction, enhanced productivity, better quality of services and the ability to focus on core business functions. In spite of the successes, there are various challenges and risks associated with IT outsourcing that may either lead to the failure of achieving the anticipated or outright losses. Nevertheless, outsourcing of IT functions from infrastructure to user support has developed a level playing field for small and big organizations alike and created totally new world opportunities. Neglecting this opportunity by organization greatly reduces its competitive edge in the currently dynamic world. Therefore, there is a need to consider the possibilities that IT outsourcing can bring to an organization, but first an organization has to learn about the success factors that determine the fruitfulness of an IT outsourcing venture by reviewing its mission, goals and objectives in light of the venture. In essence success factors are the aspects that need to be right or put in place to ensure an IT outsourcing venture attains success. The success factors are critical managerial areas of focus in the implementation of IT outsourcing, which are important in 
determining the positive performance of any IT outsourcing venture. As such, success factors need to be granted greater attention. For any organization to determine its success factors in an IT outsourcing venture, it has to first review its goals and objectives. Firstly, there is a need to know why an organization is outsourcing. Is it for cost effectiveness? Is it for better service provision or for greater flexibility? Best practices from survey studies of successfully outsourced IT functions show that disciplined vendor selection, judicious and prudent planning as well as commitment to collaborative association management include the main success factors in the process of IT outsourcing.

The first and probably most important success factor that will influence how successful an IT outsourcing plan can get is the clear drafting of goals and objectives of the client firm. Different organizations partner with third-party providers because of clear reasons and these reasons differ from one organization to another. Therefore, organizations need to determine their priorities and rank them accordingly. Failure to do this may lead to a blind entry into an outsourcing plan without understanding how the partnership will improve the performance of an organization with regard to achieving its mission and goals. For example, if the goal is the attainment of cost effectiveness, there should be a clear reduction in production costs and/or transaction cost through cutting down on costs such as monitoring costs or product development costs as part of the IT outsourcing. The attainment of these cuts on overheads is the determining factor which will ensure cost effectiveness is attained as positive product of IT outsourcing. Therefore, there is a clear need to have properly predetermined goals. Having rightly set goals also helps facilitate consensus within an organization which is necessary for kick off.

It is also an important factor to consider creating an all inclusive approach and process to IT outsourcing. The fact that the process will affect most people requires that the deliberations on the process should include all stakeholders. Failure of inclusivity is often cited as the major reason of failure in most IT outsourcing projects. This lack of inclusion may also possibly generate greater risk for the outsourcing project. Unlike other IT related changes, outsourcing does not only transform technological use and processes, but also affects business prospects, livelihoods and operations as well as employees. As such, it is highly likely to bring about change resistance and inflame emotions and politics because jobs and responsibilities will be probably placed on the line by such outsourcing projects. Inclusivity helps in the collective clear setting of goals, and thereafter allows the building of consensus to prevent change resistance within. This also helps expectations to be set on deliverables from the client side and thus helping setting up contractual agreements.

The determination of an organization's weaknesses and strengths is also an important critical factor. This prevents the probable vendor from making discoveries on IT system deficiencies and thus raising internal tension, which may set a wrong starting for the relation. Internal discovery processes are not only efficient in facilitating decision-making but they also add to the development of inclusivity. Therefore, the firm and its departments should be allowed to make internal discoveries of deficiencies and talents as well as their IT asset base so as to come to the negotiating table with good information to kick start the relation drafting with the vendor. The performance of an internal audit should be coupled with a good review from the vendor to ensure all possible systemic problems are cited and included in the service provision list which will be used to define a more robust system that is externally enabled. Therefore, a collaborative approach is essential in this case and it greatly helps in reaching a comprehensive understanding about the desired system.

Evangelization of the IT outsourcing changes is necessary because such projects are bound to affect the livelihood and day-to-day operations of an organization and thus affecting employees. These effects are likely to attract change resistance if there are some jobs at stake and this may hamper the success of the IT outsourcing project. Communicating and marketing the intention to outsource IT functions prevents fear of the project and generates enthusiasm among the employees and other stakeholders and thus elicit the support of the system. In this regard the top management is supposed to show commitment and belief in the system. This process should also be participative and not on-way directed so as to enhance inclusivity and resultant cooperation. This outreach process is not only essential in curbing resistance, but also in the eliciting cooperation from the all stakeholders, which is actually necessary for success in the project.

Management of relations and monitoring of third party providers is also a success factor, which is very essential in determining success. A large number of outsourced services often result in poor services, when their undertaking is not well monitored by the outsourcing company. Outsourcing does not mean a total delegation that leaves no responsibility within the organization, but rather a provision of more free time to engage in core activities and spare occasional time to monitor and assess the outsourced IT functions. Firms seeking to gain from agility and creativity of their third-party providers should consider being close more often with their providers to this is attained. Therefore, there is a need to have close relations with provider in order to be sure to succeed. Managing the relation between the provider and team members is essential to ensure that no conflicts emerge and that conflicts are solved. It should be kept in mind, that even though the functions are outsourced the provider is akin to a department in the company whose overall relation to the organization is essential in better performance and occasional correspondence and team-working is necessary for this to take place.

The show of commitment and dedication by the top management is also a very essential element that is critical to the success of an organization in IT outsourcing. This is because most employees need to develop some form of trust in an organization's intentions before they can fully appreciate to be part of them. Lack of commitment or laxity 
on certain goals may either show that they are not important or they may be insignificant to the organization. A show of commitment makes it easier to convince stakeholders about any course in a business organization. The development of commitment by top management also helps them in not only building their own confidence to sell the idea, but internalize and be part of it as an organization.

The success factors to IT outsourcing often have antagonists, which tend to undercut the success that could possibly be realized through the It outsourcing. There are various factors that have such an influence and some of them are directly related to the already cited success factors. For example, the lack of exercising inclusivity, which ensures that all stakeholders participate actively in the out sourcing role often, results in, challenges such as the emanation of resistance to the proposed IT outsourcing change. Resistance to change is a common phenomenon in most changing environments and there are a number of proven managerial strategies to overcome it. If not well handled, the resistance could stifle the process and fail to generate the necessary cooperation required to carry out a comprehensive internal audit, which identifies the necessary processes to be outsourced and physical requirements for the success of the business.

Another common challenge is the vendor selection process and decision-making. Currently, the market is flooded by third-party service providers that offer different forms of services under different contractual arrangements and without the right aid of an internal IT expert that understands the organization and its needs as well as the characteristics of the providers, the organization seeking to outsource IT services may fail to identify the right company to contract with and end up with a poor provider that may either offer substandard work or lead to further confusion by introducing systems that may not be compliant with the market system.

A failure on contract management is also part of a serious challenge in IT outsourcing. Third-party companies may receive IT outsourcing contracts, but there is no guarantee that they will perform. Collaboration and monitoring from the parent outsourcing company is the most basic ingredient that will guarantee success in any organization. It is often possible that some IT outsourcing bids do not yield the intended positive results, especially when the concerned clients do not often follow up to ascertain quality performance.

\section{Different Outsourcing Contracts and their Success}

Outsourcing contracts greatly define the success of any contractual agreement on IT outsourcing and business in an organization that seeks to outsource all or part of its IT functions. Outsourcing contracts are broadly divided into two namely incentive contracts and fixed fee contracts.
Simple fixed fee contracts denote contractual arrangement $\mathrm{s}$ which the vendors' payments are fixed, but the provider is allowed to re-negotiate for additional pay for variations that may lead to a rise in costs. In the fixed fee contractual arrangement the provider takes care of all risk of cost increases. In such contractual arrangements if the vendor is able to enhance efficiency, then, s/he is able to attain higher profit. In actual practice the provider has the capacity to engage in opportunistic bargaining. In such cases the vendor can pressure the client to foot the overruns in cost. This is especially the case when the client outsources to one vendor and therefore may have no option to change vendors. Fixed arrangements may also be classified as cost plus contracts (CPC), which includes the risk of additional costs only being borne by the client.

The second category of contracts known as incentive contracts ensure that there is some form of cost-sharing between the vendors and clients. These types of contracts set an expected level of performance and respective incentives if this is attained as well as penalties if underperformance is the case. Incentives and penalties are an essential part of IT outsourcing because these serve as inducements for the providers to perform highly. These also enable the outsourcing firm to have control over the outsourcing process, which enables it to manage practices such as shirking the process of business. The two act as a stick and carrot by which the outsourcing firm can try to elicit performance from the vendor.

Incentive contracts can be divided into two namely the "variable incentive contracts" (VPIC) and "fixed price incentive contracts" (FPIC). These two types of incentive contracts have a penalty and incentive provisions. The two however differ with regard to how they control the possibility of vendor under-performance. The fixed type is applicable in cases where the vendor and the outsourcing firm are both aware of the information processing cost. In such arrangements the outsourcing firm agrees to pay part of the total amount of the contract prior to the undertaking of an activity. The process requires a post-performance audit to be undertaken first. If the assessment the provider is found to have under-performed then a penalty is imposed. But if the provider lives up to the performance standards set then s/he is paid the rest of the contract's fee. In order to elicit better performance the outsourcing firm may also offer extra incentives in form of pay for any higher than stipulated performance obtained. This form of incentive setting may encourage the provider to perform better and to higher levels than anticipated by the outsourcing firm. On the other hand, the variable incentive contract is often applied whenever associated costs of processing activities may not be known. In such contractual agreements the outsourcing firm should guarantee the provider some minimal profit rates and a chance to increase the rate by operating at high performance levels and cost cutting. Therefore, the outsourcing firms have to agree to offer specific profit rate for a specific set level of performance. As such, there is a need for conducting an audit 
on performance and the information processing costs. The audits are basic in determining whether a penalty or incentive will be necessary and at what level this can be based. These are the best kind of performance enhancing contracts because of their incentivized structure, which attracts the urge to work harder to reach targets. The element of assessing performance levels also allows target setting and thus allows progress and gains to be made quantifiable.

Contracts may also be divided into two major types depending on structural plans for outsourcing, and these are conventional outsourcing which includes a contract with a vendor to provide services for an organization and the development of an IT subsidiary (quasi outsourcing) in which an organization develops an independent outsourcing firm to carry out its IT functions by contracting a department that is made almost independent. The vendor-client relation has shifted to the 'middle' and a variety of contract agreements have developed. These contracts may range from partnerships to tight contracts. Quasi-outsourcing contracts involve partial transfer of IT functions and its idea is to convert an existent IT department into a full-fledged entity, which is able to perform IT functions for an organization. This contractual agreement converts an internal department to act as an independent external vendor. This contractual arrangement is convenient because it frees internal departments initially involved in bureaucratic models to operate in a free-styled manner. According to Geyer and Barthelemy, quasi-out-sourced departments are only likely to be successful in cases where they are fully permitted to exercise autonomy. However, this is always a challenge because they are semi-autonomously independent. Independence may be misused, but it is also necessary for any organization to act independently because this helps it in making independent decisions that will determine how well an organization performs. Therefore, while a quasi-independent contract offers a free area of operation without restraints to any formerly constrained IT department it also opens a chance of excessive control that is restricting in nature and scope. The success of quasi-outsourced departments in IT outsourcing is however dependent on how well an organization is able to acquire other external contracts other than the mother company contracted work so as to supplement the work requirement which matches its abilities. Underutilization that results in most cases when a third party is unable reach its full potential due to minimal workloads may lead to poor success in IT outsourcing. This scenario is best exemplified by Sears and Mellon Bank, which failed to attain success in IT outsourcing after quasi-outsourcing because they could not attain a significant share of the external market necessary to determine their success. On the other hand, firms such as Philips that were able to acquire a substantial external market to supplement their subsidiary's work were able to perform much better.

Conventional outsourcing on the other hand offers too much freedom to the involved third party providers. The fact that the providers are not under the umbrella of the outsourcing organization, may either lead to laxity or inability to conform. Information processing contracting leads to a significant loss of control on company practice activities. The associated loss in this case may lead to opportunistic bargaining and shirking. Opportunistic bargaining in this case denotes a situation in which the vendor may demand too much and higher than the market prices. On the other hand, shirking denotes a case in which the vendor underperforms according to the contract specifics. The challenges on bargaining get worse when the outsourcing firm is locked on to one vendor and this would lead to a case where the firm may incur higher costs when trying to switch vendors.

Outsourcing contracts on IT are at times multi-vendor based and one organization can outsource to a number of vendors that specialize on different aspects of IT or different structures and platforms of its IT operations. The inclusion of multiple vendors in an organization's outsourcing bid makes the whole structure quite challenging and such a scenario requires entry into different types of contracts and the multiple contractual agreements make the whole relation complicated to handle because at times the areas of operation may overlap. This complication may however be easily overcome by ensuring that vendors sought for IT outsourcing have the capability to offer a wide array of services that can possibly cover all the needs of an organization. The inclusion of multiple contractual arrangements in an IT outsourcing project makes operations complicated and less likely to get successful. On the other hand, ensuring that a firm consolidates most of its IT outsourcing under one third-party provider is more likely to make an IT outsourcing bid more successful.

\section{Types of Activities That Can Be Successfully Outsourced}

As a rule of thumbs non-core functions are the best candidates for outsourcing in IT, whereas IT functions related to core functions should least be outsourced. Storage of records and their digitization is perhaps one of the most commonly outsourced business activities. However this does not mainly involve sensitive information and records. A large number of back office activities, which lack sensitivity and the need to maintain privacy and confidentiality are easily outsourced without any legal or otherwise requirements. Billing and payroll activities are good examples of back office activities that have been successfully outsourced. Passive business activities such as database creation on records and data mining as well as record keeping can be easily outsourced. This is mainly because they do not involve sensitive business or client information. Check processing is one example of services commonly outsourced by the banks. Knowledge process outsourcing is also commonly practiced for information that may not have sensitive analytics about a business.

On the other hand, the handling of actively involving business procedures that entail client inclusion and the 
handling of personal client information should not be outsourced because these form part of the core functions of the business. For example, functions that involve handling of sensitive client information are better off kept in-house unless the vendor is able to guarantee security. The outsourcing of business activities that directly deal with the clients should also be discouraged unless necessary. For example, the outsourcing of help-desk services may not be appropriate, especially when the users place their first calls about a product or service problem. This information is an important indicator of IS services and is helpful to the organization because it helps the organization to learn about what clients think about the services and goods provided by an organization. Therefore, it may not be effective to depend on different entities to know what people think about the firm's products and services. It would rather be appropriate if the business person learned directly from the clients about what the people think. As such, it may be appropriate to maintain help-desk services in-house, but outsource activities such as call centers meant for technical support.

The outsourcing of other business practices is quite challenging. For example, the development of information technology pieces of applications that can be patented may easily raise conflicts over ownership, especially if such tasks are outsourced. As such, in order to avoid such conflicts the development of such IT products is better if always kept in-house. Additionally, outsourcing information technology product and applications' development limits and reduces the innovations and innovative capabilities of an organizations workforce and as such these should better be kept in-house instead of being outsourced. The development of sensitive IT systems such as those concerned with security matters and preservation of privacy and confidentiality should be kept in-house so as to prevent possible breaches of security and IT system compromise. Figure. 1 below shows the percentage of IT Functions presently or likely to be outsourced while the outsourcing by department is shown in Figure-2.

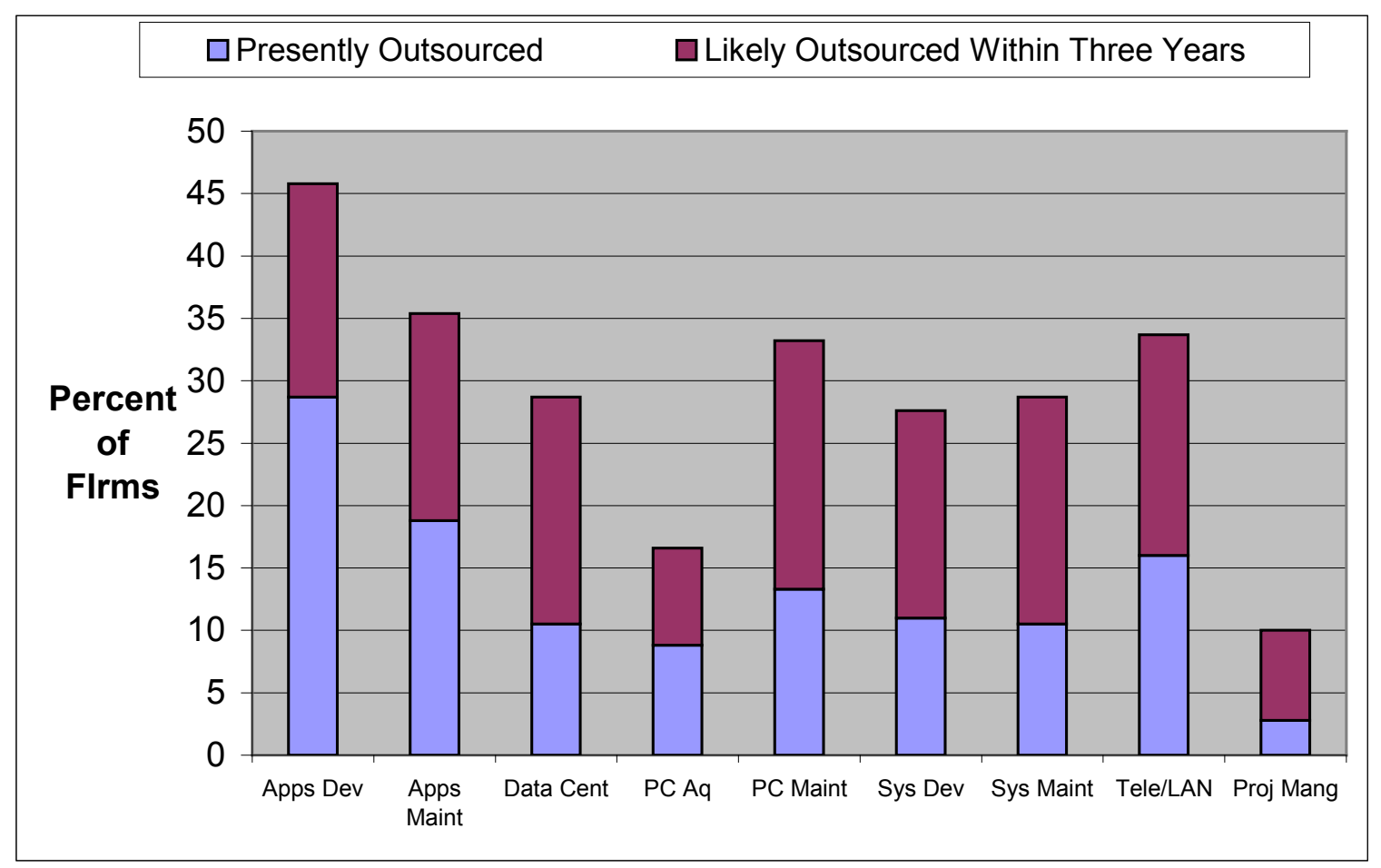

Figure 1. IT Functions Presently or Likely to be Outsourced 

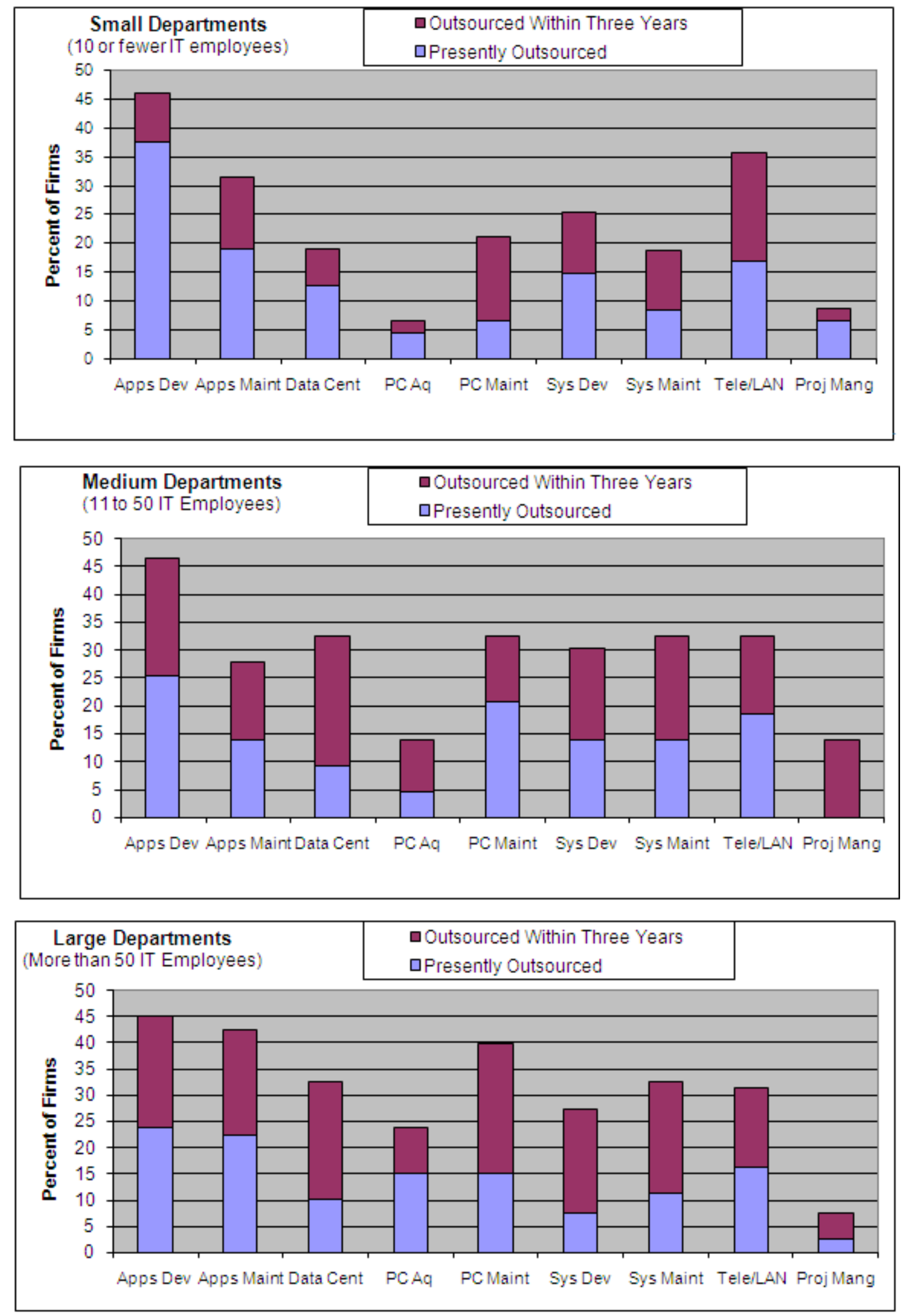

Figure 2. IT Functions Presently or Likely to be Outsourced by Department Size 


\section{Pricing in Outsourcing Relationships}

The three basic forms of procurement contracts are: (i) cost-plus; (ii) fixed-price; and (iii) gain-sharing. Price structures influence not only the incentives for both parties but also their interaction costs and the provider's future negotiating position. According to Auguste et al. (2000) the two most common pricing choices-cost-plus and gain-sharing - have destroyed value more often than they have created it. With cost-plus contracts, providers lack any incentive to reduce costs. Customers sometimes believe that such contracts will save them money by capping the provider's margins. But cost-plus contracts also limit the incentive of the provider to squeeze costs, because such contracts guarantee the provider a profit margin that no longer depends on the efficiencies it can realize by innovating, by exercising its purchasing power, or by hiring more productive staff.

A gain-sharing contract better motivates the provider to innovate and to reduce operating costs. However, it also raises interaction costs. In gain-sharing contracts, the parties agree on the baseline cost of providing a service. If the cost turns out to have been underestimated, the provider receives the difference. If the actual costs are lower than the baseline, the difference is split between the two parties in an agreed ratio. This is the most expensive kind of contract to negotiate and monitor because the parties have to define and accept precise cost projections for every situation. If the savings are lower than expected, further negotiations, in which each party blames the other, are almost inevitable. The incentives to innovate are also limited. Customers of one leading facility-management firm scrapped or modified gain-sharing contracts that had yet to expire. This occurred because the infra-service provider, having reduced costs "too much", was reaping too large a windfall. Both costs-plus and gain-sharing contracts extract a price from infra-service firms as well by revealing their costs and profits (thus betraying their future negotiating position).

Auguste et al. (2000) have suggested that fixed-price contracts are a better option. When prices are fixed, providers keep the rewards from process innovation. This kind of contract is also less costly to negotiate and does not require customers to be continually auditing their provider expenses (as they are required to do under costs-plus and gain-sharing contracts). On the other hand, these authors have observed that the pricing model to be applied must consider each specific situation and, although providers should try to negotiate fixed-price contracts for their services, they must recognize that in all likelihood they will have to adopt different pricing schemes for different services. The choice of pricing scheme will depend on the receptiveness of the customer and the underlying economics of the offering.

\section{Case Study}

The present study approached the problem of the measurement of gain-sharing as one of the components of the remuneration policies for services adopted contractually among companies. The case study that follows focused on the relationship between two large international companies that operate in Brazil. For reasons of confidentiality, the companies are referred to as 'services receiver' (SR) and 'services provider' (SP). SR operates in the credit card market, and administers a wide network of affiliated establishments while centralizing all completed card transaction operations under its brand name in Brazil. To accomplish this, SR depends on the technological and operational support of SP, a company that renders IT services for large-scale companies and governments throughout the world. The services that SP provides for SR involve capturing, processing, and transmission of data, and the execution of call-center functions for the affiliated establishments.

The pricing policy in the outsourcing relationship between SP and SR is based on the cost-plus model, with the total cost of services rendered monthly by SP being charged to SR with additional fixed remuneration. The differential aspect of the relationship between these companies is the fact that, apart from the cost-plus remuneration, there is a special contractual agreement related to gain-sharing. The gain-sharing computed yearly must be shared between the companies equally.

\subsection{Environment and Companies}

The global process of change is having significant effects on the Brazilian economy. The principal characteristics of the Brazilian economy in recent years have been:

- low economic growth;

- gradual opening of the economy;

- privatization;

- relative stability of prices; and

- technological advances

These characteristics have been especially marked in the telecommunication and financial industries, which are passing through significant market and structural transformation. Under the supervision of the Central Bank of Brazil, the financial system is gradually implementing a new Brazilian system of payments - through which diverse financial institutions will be interlinked and will carry out transactions on-line in real time among themselves, the Treasury, and other large-scale companies.

The credit card market is globally dominated by a few large brand names-American Express, Credicard, Diners, MasterCard, and Visa. Usually, the rights of exploration of these brand names (also known as 'flags') belong to specific investor groups. These authorize the use of the brand names in various countries, utilizing contracts that involve stock participation in a new enterprise, and thus producing an attractive worldwide business.

\subsection{Service Receiver}


The service receiver in this case study (SR) is the holder of the exclusive right of use in Brazil of one of the prominent 'flags' of credit cards. Its stock control belongs to a group of large financial institutions that also operate in the country, apart from the participation of the 'flag's' own international brand. SR has a large number of affiliated establishments and users of this brand of credit card in the commercial service sector. Through the credit card, the user can make purchases in one payment, or parceled out in various payments, from an international network of affiliated establishments to the brand. The user can also use the card to pay for purchases directly by debit in the user's deposit account of the financial institution with which the user maintains a relationship. The user can also make cash withdrawals in other countries. The ready acceptance of credit cards is drastically modifying the profile of transactions made in Brazilian retail trade, and has significantly increased the volume of transactions made by operators.

SR opted to outsource some its activities because of:

- operational difficulties associated with the growth in transaction volume;

- a need to maintain a focus on its main business; and

- the need to develop new competencies (for example, in information technology).

SR relies on the support of SP to accomplish activities that require a high level of information technology-especially those that, although they are not core to SR's business, are essential to its success in this changing environment.

\subsection{Service Provider}

The service provider in this case study (SP) is a large company with branches in several countries. The company is a provider of information-technology services, and administers complex data and voice communication networks. SP has absorbed all of the IT activities related to SR's transactions in Brazil-including the capture, processing, and transmission of all data. These activities involve direct communication with:

- affiliated establishments (merchants) to the brand name in Brazil;

- the receiver banks (where the merchants maintain their checking accounts); and

- the national and international issuing banks. Figure-3 represents the arrangement.

The transaction data are captured by SP by electronic or manual means. Approximately $95 \%$ of transactions are electronic. The data are captured by the affiliated establishments and immediately sent to an exchange headquarters at which a decision is made on whether the transaction should be authorized. If authorized, the data of the transaction are stored, processed, and transmitted by SP to the receiver bank (where the merchant maintains its deposit accounts) and to the issuing bank (where the card user maintains its accounts). Credits and collections are realized, and this results in an accomplished transaction.

In this process, speed, security and low cost are critical factors that determine the success of the business. The decision of SP to outsource these IT activities takes into account these factors of process, speed, security and low cost, as well as the need for SP to maintain focus on its main business by delegating activities that require highly specialized know-how.

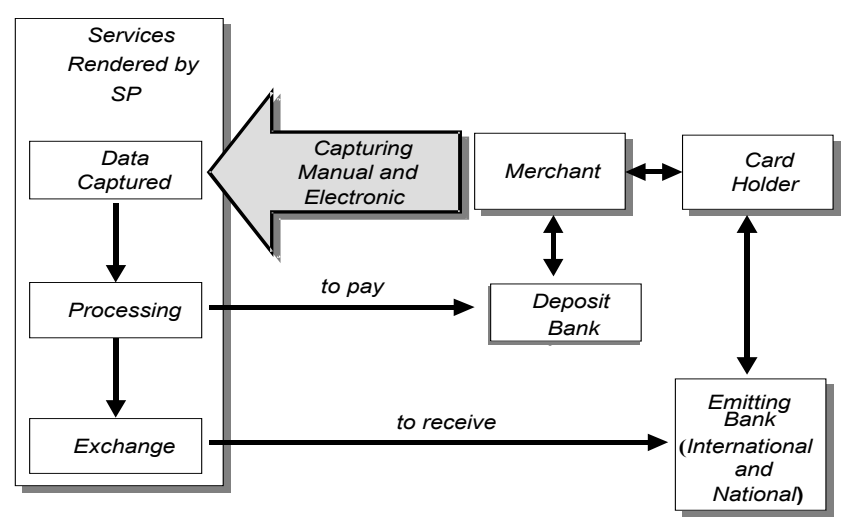

Figure 3. Operational flow of the credit card business

The services rendered by SP for SR involve the following activities:

- development and maintenance of systems;

- maintenance of database of the clients;

- capturing, processing, and transmission of transaction data;

- call center service;

- operational support to the affiliated establishments; and

- back-office services.

\subsection{Costs in Outsourced Activities}

The costs incurred in the outsourced activities are:

- administrative;

- telecommunications;

- physical space;

- hardware;

- software;

- maintenance;

- computer usage;

- outside labour; and

- support

The distribution of costs incurred in the accomplishment of the outsourced activities are shown in Table 1.

Table 1. Distribution of costs by category

\begin{tabular}{cc}
\hline Costs & Distribution \\
\hline Support & $43 \%$ \\
Computer Usage & $27 \%$ \\
Outside Labor & $14 \%$ \\
Other Costs & $16 \%$ \\
Total & $100 \%$ \\
\hline
\end{tabular}


Table 1 shows that the principal elements of costs are support (43\%), computer usage $(27 \%)$, and outside labor (14\%). Collectively, these respresent $84 \%$ of the total costs.

These costs are incurred at the level of administrative units. The administrative units are cost centers-which can be either operational or support. The operational cost centers (OCCs) execute production and costumer-service activities linked directly to the accomplishment of the transactions (manual or electronic). The support cost centers (SCCs) execute support activities to the $\mathrm{OCCs}$ - such as system development, planning, training, and other back-office activities. Taken together, the OCCs generate $66 \%$ of the total costs, whereas the SCCs generate $34 \%$.

The cost centers are basically structured as fixed costs, with the most significant of these being support, computer usage, and outside labor. The major support costs are: (i) the salaries and wages of personnel; (ii) the costs of computer usage, expressed as computer processing units (CPUs); and (iii) the costs of outside labor. Of these, wages costs are essentially the same in OCCs and SCCs., computer costs are more significant in OCCs than in SCCs, but outside labor costs are greater in SCCs than in OCCs.

Some elements of fixed costs (such as wages) are valid for short periods of activity whereas other elements of fixed costs (such as costs of hardware and software) are valid for larger periods of activity. Typically, fixed costs refer to the use of resources that possess a limited capacity for production. Within a determined interval (range) of activity of any given cost center, the fixed costs remain constant (provided that production capacity is not surpassed). However, if the installed capacity were to be increased, a larger quantity of fixed resources would be required. As long as the new installed capacity is not surpassed, the amount of fixed costs will remain constant. OCCs, for example, have a planned structure of resources (equipment, software use licenses, people, physical space, and so on) to process a predetermined volume of transactions (with the time of computer use constituting the unit used to measure the work). Above this limit, investments in new resources become necessary, thus elevating the production capacity to a new higher level and expanding the range of activities.

In planning the necessary resources for a given cost center, the number of transactions and the use of computer time might be important, whereas, for another cost center, the number of employees or the size of the area to be attended might be more relevant.

In this case study, it is significant that the total costs were basically formed by fixed costs - that is, there was no direct proportional relationship between these costs and the volume of processed transactions. Figure-4 shows monthly transaction volume compared with the annual total costs and unitary costs.

\subsection{The Gain-Sharing Measurement Problem}

As previously noted, several studies consider different aspects of outsourcing relationships. However, no study has specifically addressed gain-sharing — apart from the work of Auguste et al. (2000), which touched on the subject.

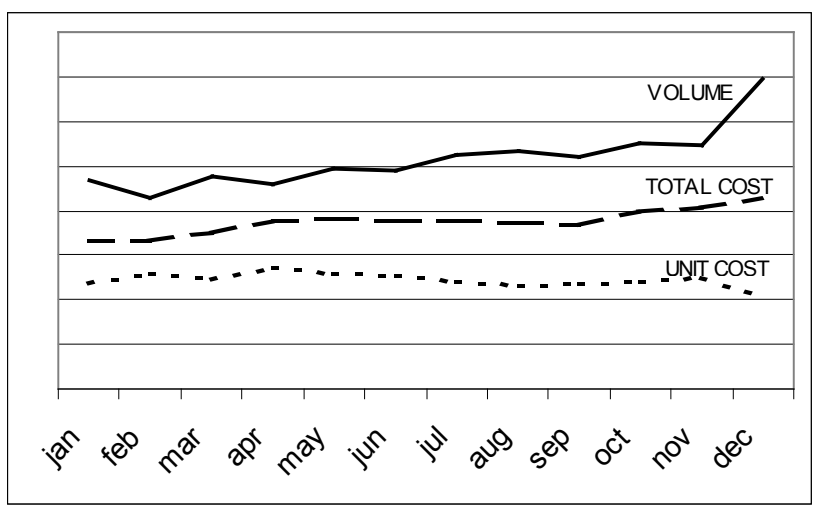

Figure 4. Transaction volume, total costs, and unitary costs

The authors of the present study define gain-sharing as the sharing of a benefit obtained by developing an activity in a more economical manner in relation to an established parameter. As an element that seeks to express the benefits realized in the business relationship between two companies, it is presupposed that gain-sharing should:

- be measured against a previously established parameters;

- reflect the effort involved in various actions that are undertaken;

- induce performance improvement;

- be objectively measurable;

- be expressed in monetary terms; and

- be mutually acceptable to the parties.

The first premise is the most important because it drives the proposed methodology for measurement of gain-sharing. According to the definition provided above, gain-sharing is related to cost savings and to cost-accounting concepts of price and efficiency. According to Horngren at al. (2000), price variation reflects the difference between actual and budgeted input prices, whereas efficiency variation reflects the difference between actual and budgeted input quantities.

In this case study, the benefits obtained from the business relationship between the companies were increased by:

- an increase in activity volume (that is, greater production); or

- a reduction in costs (that is, less consumption).

The gains produced by increasing activity volume generated an additional contribution margin to SR, proportional to the volume of business. The increment in the activity volume was promoted by SR, whereas SP supported the growth and made it possible by allocating resources (human, physical, and technological) and adjusting the capacities of the various activity centers. SP was responsible for being pro-active in implementing technological and operational solutions to meet the levels of activity reached by SR. Therefore, although SP did not increase activity volume, it did produce an intangible benefit by assisting in the processing of a larger volume of activity. This required more responsibility, larger operational risk, and less flexibility. 
This benefit should not to be confused with gain-sharing, but it should be included (and remunerated) in the pricing agreement between the companies - in accordance with the premise that the return should have relationship with the investment made and the risks assumed. It would be unjust to maintain a fixed level of remuneration to SP for assisting in volumes of services significantly higher than those originally assumed. Although it clearly generates a benefit for SR, this matter should be treated in the pricing policy of the services, rather than through the concept of gain sharing.

In contrast, the gains that SP provides to SR through cost savings (when less resources are consumed than previously assumed) should be classified as gain sharing. This is because:

- the costs are entirely transferred to the buyer of the services;

- the gains are forwarded to the buyer of the services;

- the gains arise from the efforts of actions undertaken;

- the gains reflect increased performance in relation to pre-established parameters;

- the gains are objectively measurable;

- the gains are measurable in monetary terms; and

- the gains are based on previously defined agreements.

In view of the above discussion, the question arises as to how to measure gain-sharing in this kind of operational environment - that is, one characterized by a high volume of fixed costs and great oscillations of activity volumes. The answer to this question is presented through the proposition of a model of measurement of gain-sharing.

\section{Proposed Model for Gain-Sharing Measurement}

The fundamental premise of the model is the existence of a parameter that is present (and can be elaborated for different volume levels) in the flexible budgets and standards of each cost center. The model is comprised of four steps.

1. Elaboration of the original budgets-taking into account the amounts and the values of the resources forecast for each volume level and for each cost center (considering its particular work units).

2. Revision of the original budgets (or elaboration of the revised budgets) - consisting of a revision of the quantities and values of the resources previously planned for each volume level and for each cost center (considering its particular work units). The revised budgets constitute the base for comparison of expenses incurred and, therefore, the measurement of gain-sharing;

3. Counting of the expenses incurred-based on the same concepts and criteria adopted in the previous phases.

4. Comparison of the expenses incurred with the constants in the revised budgets-allowing a measurement of gain-sharing and an evaluation of the contribution of the cost centers (and the diverse elements that make up their costs). The comparison between actual costs and estimated costs allows the measurement of cost savings to be obtained.

As previously noted, the amount of fixed cost stays constant within a determined interval of activity. The measuring of the savings of fixed costs is through a comparison of the forecast total value of expenses (for a given level of activity) with the actual total value of the expenses incurred. The following situations can occur.

i. The actual activity volume is not the same as the planned volume, but occurs within the relevant interval

In this case, the economy of fixed cost should be computed by comparing the total value of planned expenses (for the level of activity executed) with the total value of actual expenses. Cost efficiency exists at any point within the relevant interval because the actual costs are smaller than the costs planned for the interval.

ii. The actual activity volume was not the same as the planned volume and it was outside (above or below) the relevant interval.

In this case, the relevant interval in which the activity volume occurs should be determined, and this should fit with the corresponding budget of valid cost for the interval of relevance. In the same way, the cost efficiency is measured by the difference between the costs incurred and the costs estimated for that interval of relevance.

\subsection{Procedures}

Table 2 shows the steps and procedures required for the implementation of the proposed model. 
Table 2. Procedures for implementation of proposed model

\begin{tabular}{|c|c|}
\hline Steps & Procedure \\
\hline $\begin{array}{l}\text { 1. Elaboration of the original budget (for } \\
\text { cost center for different levels of } \\
\text { volumes) }\end{array}$ & $\begin{array}{l}\text { - } \text { define work units of the cost centers; } \\
\text { - } \quad \text { define the volume intervals of the work units; } \\
\text { - consider the physical amounts of resources; } \\
\text { - } \quad \text { consider the unitary values of the resources; } \\
\text { determine the total values (quantities x prices); } \\
\text { consider the total values of the resources for which there there are no estimates of physical } \\
\text { amounts of resources. }\end{array}$ \\
\hline $\begin{array}{l}\text { 2. Revision of the original budget (for } \\
\text { cost center for different levels of } \\
\text { volumes) }\end{array}$ & $\begin{array}{l}\text { - } \quad \text { confirm the work units of the cost centers; } \\
\text { - } \quad \text { ceschedule the volume intervals of the work units; } \\
\text { - } \quad \text { revise the physical amounts of resources of the original budget; } \\
\text { - } \quad \text { devise the unitary values of resources of the original budget; } \\
\text { revise the total values of the resources for which there there are no estimates of physical } \\
\text { amounts of resources. }\end{array}$ \\
\hline $\begin{array}{l}\text { 3. Counting of the amounts realized by } \\
\text { cost center (for cost center for the level } \\
\text { of volume reached) }\end{array}$ & $\begin{array}{l}\text { measure the actual volume of work units occurred; } \\
\text { - measure the actual total values consumed of resources; }\end{array}$ \\
\hline $\begin{array}{l}\text { 4. Determination of the efficiencies of } \\
\text { costs (for cost center for the level of } \\
\text { volume reached) }\end{array}$ & $\begin{array}{l}\text { - count, for cost center, the variations between the actual values and the revised estimated } \\
\text { values, established for the volume of work units occurred; } \\
\text { determine the occurrence of gain-sharing through the consolidation of values of the total } \\
\text { variations of all cost centers, considering that gain-sharing exists only when the total amount } \\
\text { of actual values is inferior to the total amount of revised estimated values. }\end{array}$ \\
\hline
\end{tabular}

Table 3. A model for the determination of gain-sharing

\begin{tabular}{|c|c|c|c|c|c|c|}
\hline \multirow{2}{*}{ Resources } & \multicolumn{2}{|c|}{ Original budget } & \multicolumn{2}{c|}{ Revised budget } & Actual & Variations \\
\cline { 2 - 6 } & $\begin{array}{c}\text { Range 1 (minutes) } \\
(300,000 \text { to 500,000) }\end{array}$ & $\begin{array}{c}\text { Range 2 (minutes) } \\
(500,001 \text { to 700,000 }\end{array}$ & $\begin{array}{c}\text { Range 1 (minutes) } \\
300,000 \text { to } 500,000\end{array}$ & $\begin{array}{c}\text { Range 2 (minutes) } \\
500,001 \text { to 700,000 }\end{array}$ & 600,000 minutes & \\
\hline $\begin{array}{c}\text { Support } \\
\text { salary } \\
\text { bonus } \\
\text { fringe }\end{array}$ & 171,122 & 207,312 & 188,234 & 228,043 & 216,056 & 11,987 \\
\hline $\begin{array}{c}\text { Outside labor } \\
\text { company 1 } \\
\text { company 2 }\end{array}$ & 16,758 & 46,726 & 18,552 & 51,640 & 55,842 & $(4,202)$ \\
\hline Computer usage & 806,458 & $1,443,473$ & 890,105 & $1,590,820$ & $1,548,994$ & 41,826 \\
\hline $\begin{array}{c}\text { Maintenance } \\
\text { hardware } \\
\text { software }\end{array}$ & 9,242 & 44,472 & 8,345 & 38,552 & 35,647 & 2,905 \\
\hline $\begin{array}{c}\text { Physical space } \\
\text { space } \\
\text { other }\end{array}$ & 8,969 & 16,865 & 9,866 & 18,552 & 19,214 & $(662)$ \\
\hline Administrative & 6,188 & 9,934 & 6,384 & 10,627 & 10,429 & 198 \\
\hline Total cost & $1,018,737$ & $1,768,782$ & $1,121,486$ & $1,938,234$ & $1,886,182$ & 52,052 \\
\hline
\end{tabular}

\subsection{Example of the Proposed Model}

In the case study under consideration, the cost center of production is an organizational area responsible for the capturing, processing, and transmission of the relative data of the realized transactions of SP. Table 3 shows the planned performance (original and revised) and the realized performance of an administrative unit in a month.

In Table 3, it is observed that the total costs originally planned for the period were $\$ 1,018,737$, for a level (range) of activity of 300,000-500,000 minutes of computer processing, and $\$ 1,788,782$ for 500,001-700,000 minutes. The revised values were, respectively, $\$ 1,121,486$ and $\$ 1,938,234$ (staying in same activity intervals). The performance realized in the month (corresponding to 600,000 minutes of computer processing) was a total cost of $\$ 1,886,182$.

Comparing the realized costs with the planned costs for the volume of 600,000 minutes, it is observed that there was a total gain of $\$ 52,052$ - which corresponds to the total of the cost variations in the period. Among the favourable variations, the most significant flowed from the use of computers $(\$ 41,826)$ and support $(\$ 11,987)$. In contrast, variations related to external services $(\$ 4,202)$ and to physical space (\$662) were negative-demonstrating that the costs were larger than forecast.

Apart from measuring the total amount of variation, the 
model identifies the favourable and unfavourable variations in cost, thus contributing to the diagnosis and ongoing improvement of performance.

\section{Conclusion}

The pros and cons of outsourcing varies by industry, size of organization, organizational structure, and many other components. Oftentimes, web or software development projects become complex, necessitating the support of additional IT professionals who specialize in more difficult aspects of projects. Information technology outsourcing is used by companies that are limited in being able to handle new or complicated processes. A task may be more efficiently performed by certified IT professionals who can work around the clock to address the more difficult aspects of the project, something it would take months to accomplish with an existing IT team.

One of the better reasons for using IT outsourcing is to adapt quickly and affordably to the demands of clients. If a company is going to compete in the market today, the company must be able to make changes and improvements quickly in order to retain consumer loyalty. Customers today demand a fast response, products and services that address their immediate needs, and affordable solutions to their problems.

Outsourcing has become necessary for many organizations. The economy has changed drastically over the past few years influencing more organizations to analyze the financial advantages or disadvantages of producing products and services in-house or outsourcing. Numerous components and variances contribute to the cost of doing business. The cost structure is the primary components of organizations. Some cost structures are fixed, variable, or mixed indicating a combination of fixed and variable. All size organizations outsource a portion of his or her business. Therefore, taking time to reflect on the points identified in this paper may enlighten or create ideas for consideration regarding outsourcing.

\section{REFERENCES}

[1] Arnett, K.P., \& M.C. Jones. "Firms That Choose Outsourcing: A Profile", Information \& Management, 26: 1994, 179-188.

[2] Athey, S., J. Plotnicki, \& Y. Ballester. "Changing Information Systems Job Requirements from 1989 to 1993", Journal of Computer Information Systems, 35: (3), 1995, 12-22.

[3] Athey, S., \& J. Plotnicki. "The Evaluation of Job Opportunities for IT Professionals", Journal of Computer Information Systems, 38: (3), 1998, 71-88.

[4] Brown, W. "ASU Grad Sees Rural Arkansas as Corporate Outsourcing Post", Arkansas News Bureau, 2004 (April $19^{\text {th }}$ edition archived at http://www.arkansasnews.com).

[5] Cappel, J.J. "Entry-Level IS Job Skills: A Survey of Employers", Journal of Computer Information Systems, 42: (2), 2002, 76-82.

[6] Cheon, M.J., V. Grover, \& J.T.C. Teng. "Theoretical Perspectives on the Outsourcing of Information Systems", Journal of Information Technology, 10: (4), 1995, 209-220.

[7] Earl, M.J. "The Risk of Outsourcing IT", Sloan Management Review, 37: (Spring), 1996, 26-32.

[8] Field, T. "Outsourced in America”, CIO Magazine, 2001 (October $1^{\text {st }}$ edition archived at http://www.cio.com).

[9] Grover, V., M.J. Cheon, \& J.T.C. Teng. "The Effect of Service Quality and Partnership on the Outsourcing of Information Systems Functions", Journal of Management Information Systems, 12: (4), 1996, 89-117.

[10] Gupta, U.G., \& A. Gupta. "Outsourcing the IS Function: Is It Necessary for Your Organization”, Information Systems Management, 9: (Summer), 1992, 44-50.

[11] Ketler, K., \& J. Walstrom. "The Outsourcing Decision", International Journal of Information Management, 13: (6), 2003, 449-459.

[12] Lacity, M.C., \& R. Hirschheim. "The Information Systems Outsourcing Bandwagon", Sloan Management Review, 35: (1), 1993, 73-86.

[13] Lacity, M.C., \& R. Hirschheim. Beyond the Information Systems Outsourcing Bandwagon: The Insourcing Response, John Wiley \& Sons, New York, NY, 1995.

[14] Lacity, M.C., \& L.P. Willcocks. Global Information Technology Outsourcing, John Wiley \& Sons, New York, NY, 2001.

[15] Lacity, M.C., L.P. Willcocks, \& D.F. Feeny. "IT Outsourcing Maximize Flexibility and Control", Harvard Business Review, 73: (May-June), 1995, 84-93. 